\title{
SURFACE OZONE MEASURED AT GLOBE SCHOOLS IN THE CZECH \\ REPUBLIC: A DEMONSTRATION OF THE IMPORTANCE OF STUDENT CONTRIBUTION TO THE LARGER SCIENCE PICTURE
}

\author{
BY JOHN K. CREILSON, MARGARET R. PIPPIN, \\ BRYANA L. HENDERSON*, IRENE H. LADD, JACK FISHMAN, \\ DANA VOTÁPKOVÁ, AND ILONA KRPCOVÁ
}

\begin{abstract}
AFFILIATIONS: Creilson-Science Systems and Applications, Inc., Hampton, Virginia; Pippin, Ladd, and Fishman-Chemistry and Dynamics Branch, NASA Langley Research Center, Hampton, Virginia; Henderson-Langley Aerospace Research Summer Scholars (LARSS) Program, NASA Langley Research Center, Hampton, Virginia; Votápková and Krpcová-TEREZA Association, Prague, Czech Republic * Now at University of California, Los Angeles, California CORRESPONDING AUTHOR: John K. Creilson, Science Systems and Applications, Inc., 1 Enterprise Parkway, Suite 200, Hampton, VA 23666 E-mail: john.k.creilson@nasa.gov
\end{abstract}




\section{ABSTRACT:}

GLOBE (Global Learning and Observations to Benefit the Environment) is a worldwide hands-on, primary and secondary school-based education and science program, developed to give students a chance to perform real science by making measurements, analyzing data, and participating in research in collaboration with scientists. As part of the GLOBE Surface Ozone Protocol and with the assistance of the TEREZA Association in the Czech Republic, schools in the Czech Republic have been making and reporting daily measurements of surface ozone and surface meteorological data since 2001. Using a hand-held ozone monitor developed for GLOBE, students at several Czech schools have generated multiyear data records of surface ozone from 2001 to 2005. Analysis of the data shows surface ozone levels were anomalously high during the summer of 2003 relative to other summers. These findings are consistent with measurements by the European Environment Agency that highlights the summer of 2003 as having exceptionally long-lasting and spatially extensive episodes of high surface ozone, especially during the first half of August. Further analysis of the summer's prevailing meteorology shows not only that it was one of the hottest on record, a finding also seen in the student data, but the conditions for production of ozone were ideal. Findings such as these increase student, teacher, and scientist confidence in the utility of the GLOBE data for engaging budding scientists in the collection, analysis, and eventual interpretation of the data for inquiry-based education. 
CAPSULE: Student measurements and observations taken as part of the GLOBE program can play an important role in both the analysis of scientific data and in the fostering of scientific curiosity.

\section{SURFACE OZONE MEASUREMENTS IN THE CZECH REPUBLIC: A GLOBE SUCCESS STORY}

\section{Introduction}

When it was first established in 1994, one cornerstone of the vision for GLOBE (Global Learning and Observations to Benefit the Environment) was that it would provide a mechanism by which K-12 students could contribute meaningfully to the earth science community. The realization of such an ideal required the development of a set of instructions and standards that ensured measurements of high enough quality that they could be published in the peer-reviewed literature. These measurement procedures were established as GLOBE protocols and more than 50 of them have been developed for the program. True to its vision, the analyses of student-obtained GLOBE data have indeed been published (e.g., Mims, 1999; Chambers and Duda, 2005; Ault et al., 2006; Boersma and de Vroom, 2006) and most of these studies, which involved collaborations between scientists, students, and educators, have focused on the use of student-derived data to validate satellite observations. 
The Surface Ozone Protocol was developed in 1998 by the S.M.O.G. (Surface Measurements of Ozone for GLOBE) team from NASA Langley Research Center in Hampton, VA, and the protocol has been used by 122 schools in 13 countries (Fig. 1). The current study features a set of measurements from schools in the Czech Republic, where the team formed an informal partnership with TEREZA, a Czech organization whose mission is to promote and support environmental education within the country. TEREZA was initially founded in 1979 with its primary purpose being a grassroots organization dedicated to protecting specific precious natural locations in the Prague metropolitan area from environmental blight. Since 1989, TEREZA has expanded its activities to the development of environmental education throughout the Czech Republic and the Surface Ozone Protocol was a natural extension of their work. Because of the unparalleled success achieved by Czech students and teachers in this study, we also examine the country's unique emphasis on environmental education that led to this accomplishment.

\section{Importance of Surface Ozone}

Over the last three decades, considerable attention has been given to stratospheric ozone depletion associated with the release of industrially manufactured chlorofluorocarbons and halons into the atmosphere. The importance of this problem arises from the fact that stratospheric ozone protects the biosphere (including human beings) from harmful solar ultraviolet radiation and that ozone depletion in the stratosphere could enhance the occurrence of skin cancer and other maladies such as cataracts. Ozone is considerably less abundant in the troposphere than in the stratosphere, but its role, on local (urban), 
regional, and global scales, is extraordinarily important. In and around urban areas, the high ozone concentrations produced as a result of fossil fuel combustion by automobiles and power plants contribute to respiratory diseases, heart problems, and eye irritation (Spektor et al., 1988; Koren et al., 1989). A multivariate statistical study by Bell et al. (2004) found that elevated surface ozone concentrations may be responsible for $\sim 4000$ deaths annually in the United States. In regions surrounding industrialized areas, high ozone levels during summer lead to vegetation damage and to the reduction of crop productivity, resulting in extensive financial losses to agriculture (Heck et al., 1983; Mauzerall and Wang, 2001). On hemispheric and even global scales, the observed increase in tropospheric ozone abundance is an important contributor to global warming and has produced a climate forcing that is significant when compared with the increased amount of $\mathrm{CO}_{2}$ since the pre-industrial era (Fishman, 1991; IPCC, 1996). Estimates suggest that tropospheric $\mathrm{O}_{3}$ contributes $\sim 0.4 \mathrm{~W} \mathrm{~m}^{-2}$, compared with $\sim 1.5 \mathrm{~W} \mathrm{~m}^{-2}$ for $\mathrm{CO}_{2}$ (IPCC, 1996)

\section{Surface Ozone Protocol}

The S.M.O.G. team was formed with the aim of bringing an understanding of the science of ozone into the classroom, including developing lessons that emphasized distinguishing between the "good" ozone in the stratosphere and the "bad" ozone in the lower atmosphere. As part of the Surface Ozone Protocol, students use a hand-held device developed for GLOBE (see Fig. 2), which determines ozone levels by measuring the color change of a chemically treated strip of paper that has been placed in the ambient atmosphere for 1 hour. At the same time, they also measure temperature, relative 
humidity, and wind direction at school monitoring stations and record cloud cover and type (Fig. 3). Students then submit their data via the GLOBE Web site

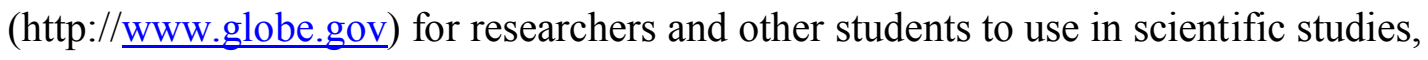
such as determining how weather conditions affect air quality. The expectation is for the students to look at their measurements in the context of the atmospheric conditions at the time of the measurement. The measurement and subsequent submission of the ozone and meteorological data provide both the students and the researchers the opportunity to visualize and analyze links between the coincident measurements.

The S.M.O.G. team, in support of the science objective to analyze the student-observed surface ozone data, develops strategies to integrate the Surface Ozone Protocol into science, mathematics, technology, and language arts. The protocol (http://www.globe.gov/tctg/ozone.pdf?sectionId=15\&rg=n\&lang=en) includes an overview of ozone chemistry in both the stratosphere and the troposphere and its environmental importance. It then describes the measurement of surface ozone and supporting measurements (cloud cover and type, relative humidity, temperature, and wind direction). The protocol contains a field guide that discusses exposing and reading the ozone test strip, as well as a section on measuring wind direction; it concludes with pointers discussed in a "frequently asked questions" section that also provides insights for determining whether or not the data are reasonable according to some "first look" criteria.

As part of the support provided by the S.M.O.G. team, teacher and student training is provided. Initial training in the Czech Republic was conducted in May 2001 and 
coincided with the national "GLOBE Games" held in Kadaň. During this 3-day event, students and teachers from GLOBE schools, primarily from the Czech Republic, "compete" using various GLOBE protocols, receive news and updates about GLOBE, and share their experiences. The competition is judged according to how correctly protocol procedures are followed and the accuracy of the observations. Each school is represented by five student-competitors, one student-journalist and two teachers. Student teams compete in various disciplines covering many of the GLOBE protocol areas, such as measuring surface ozone, measuring the amount of dissolved oxygen in lake and river water, working with a GPS, measuring soil temperature, accurately recording cloud cover and type, and numerous others. They also have fun at the sites, playing the $\mathrm{pH}$ game or participating in special teambuilding tasks. One group of students works as reporters, preparing a special edition of the GLOBE Newsletter for distribution to the participants at the closing ceremony. Every year TEREZA prepares and organizes the GLOBE Games in close cooperation with a GLOBE school, which often results in community-wide cooperation, uniquely fostering the spirit of TEREZA's goal of promoting widespread environmental awareness.

During the 2001 initial visit, the S.M.O.G. team met with 45 teachers and 250 students, first working the teachers through the protocol and then providing ideas for integrating the protocol into their curricula, in this case the study of ozone with mathematics. Next, the team instructed students in methods: how to calibrate and place an unexposed chemical strip, observe cloud cover and type, and record current temperature, relative humidity and wind data (Fig. 3). The students then repeated this process when they 
returned 1 hour later to read the exposed strip. Follow-up training was conducted in September 2003 and focused primarily on the students as well as recognizing schools that had been providing consistent, high-quality data. During this visit, students demonstrated their data gathering procedures and discussed analytical strategies with the team.

\section{STUDENT DATA COLLECTION IN THE CZECH REPUBLIC: WHERE EDUCATION MEETS SCIENCE AND BOTH WIN}

\section{Czech Republic Student Ozone Data}

Thirteen schools in the Czech Republic have been involved in making daily surface ozone measurements in support of the GLOBE Surface Ozone Protocol since 2000 (even before the S.M.O.G. team's first visit to the Czech Republic). Six of these schools (Fig.4) were recognized for their excellent collection of ozone data sets. Two schools located in Jičín and Vítkov have the longest and most complete data records spanning from the summer of 2001 through the summer of 2005. A time series of the student data from both schools can be seen in Fig. 5. Both time series clearly show the annual cycle of ozone where the highest levels are always found in late spring and summer. The individual student measurements also capture the variability in daily surface ozone concentrations, an important finding considering the impact that daily fluctuations in prevailing meteorology have on surface ozone distribution. 


\section{Consistency with European Union Ozone Data}

The European Commission (EC) collects ozone information from both European Union (EU) and non-EU member countries and has nearly 2000 reporting stations, primarily clustered around urban centers; 69 stations were located in the Czech Republic where ultraviolet absorption photometry is the method of measurement. The EC requires these countries to report monthly ozone exceedance information in accordance with two thresholds: 1) a population information threshold, which is defined as the one-hour average concentration of $180 \mu \mathrm{g} / \mathrm{m}^{3}$; and 2) a population warning threshold, which is defined as the 1-hour average concentration and was set at $360 \mu \mathrm{g} / \mathrm{m}^{3}$ for years 2001 to 2003 and is now at $240 \mu \mathrm{g} / \mathrm{m}^{3}$ (for years 2004 to the present). The change in this threshold was due to an updated European directive that was effective following the 2003 season. The difference between the two 1-hour threshold requirements is the warning threshold requires an action plan if the concentration is exceeded for three consecutive hours (EEA, 2003; 2006).

\section{Summer of 2003}

The summer of 2003 over Europe was exceptionally warm, especially throughout central Europe. Based on temperature reconstructions, the summer of 2003 was very likely warmer than any summer back to the year 1500 (Luterbacher et al., 2004). Compared with the 1901 to 1995 average surface temperature, this summer exceeded the average by $\sim 2^{\circ} \mathrm{C}$. 
According to a report by the European Environment Agency (EEA, 2003), the summer of 2003 also had exceptionally long-lasting and spatially extensive episodes of high surface ozone, especially during the first half of August, and in terms of exceedances of European ozone information threshold values (set to $180 \mu \mathrm{g} / \mathrm{m}^{3}$, equivalent to $90 \mathrm{ppbv}$ ), the summer of 2003 was considered record breaking (Fig. 6). An analysis of station exceedances for the Czech Republic shows that $80 \%$ of the stations (49 out of 61 ) in 2003 reported at least one exceedance, whereas only 12 to $23 \%$ of the Czech stations reported at least one exceedance in the other years between 2001 and 2005 (EEA, 2006).

During summer 2005, a college student joined the NASA-Langley S.M.O.G. team to help analyze the Czech student data. Fig. 7 shows the average summer surface ozone and temperature measurements made by the students at Jičín and Vítkov for 2001 to 2005. The most striking feature in both Figs. 5 and 7, for Jičín in particular, is the extremely high ozone concentrations seen during the summer of 2003. The difference in ozone concentrations between the two schools for this summer is most likely due to a combination of the prevailing meteorology for that summer and the location of the schools relative to a major city. Jičín is located $85 \mathrm{~km}$ northeast of Prague, and during this summer the prevailing winds were from the south-southwest; thus transport from a more urban location to a more rural location could be contributing to this marked increase. A similar situation occurs in the Los Angeles metropolitan area, where pollution from the city is transported approximately $100 \mathrm{~km}$ downwind to Riverside, where higher ozone concentrations are often measured (Turco, 1997). Fig. 7, consistent 
with the EEA data shown in Fig. 6, clearly illustrates how anomalously high the pollution levels were throughout Europe during the 2003 summer.

An analysis of meteorological data shows an anomalously strong anticyclonic circulation (i.e., high pressure) over Europe during the summer of 2003. Common characteristics with these high surface pressure systems are lower surface wind speeds and subsiding air, factors that lead to weak ventilation of the boundary layer, potential subsidence inversions, and a subsequent build-up of local emissions (Turco, 1997). Coupled with record-breaking surface temperatures, these stagnant conditions resulted in the creation of ideal conditions for the formation of tropospheric ozone. An analysis of summer surface temperature and wind data from the National Center for Environmental Prediction (Kalnay et al., 1996) shows uncharacteristically low wind speeds and high surface temperatures during the summer of 2003 (Henderson et al, 2005). Because temperature and winds are strongly related to ozone production, it is likely the high ozone amounts reported by the EEA and confirmed by the students in the summer of 2003 result from the anomalous weather patterns observed that year. Fig. 7 not only shows highly correlated temperature and ozone anomalies for the summer of 2003 but, when combined with other GLOBE-observed features of below-average cloud cover and lower humidity, it is clear that the student data were able to identify an important pollution event and the necessary conditions that led to its formation. 


\section{Comparison of Czech Student Data and Czech Hydrometeorological Institute Data}

A comparison of student data from Jičín and station data from the Czech

Hydrometeorological Institute (CHMI) for May 2004 (time period when both sets of data were available) shows good agreement between the two and more importantly it shows that the student data capture the daily variability evident in the station data (Fig. 8). This level of agreement gives the scientific community confidence in the use of the data. The Jičín measurements were taken daily at 10 a.m., a time of the day when the concentration of surface ozone is generally increasing rapidly; thus it is noteworthy that both the student measurement and the official CHMI reading can be accurate despite the observed difference. As of 2005, the Czech Republic had 69 reporting stations for ozone (3.6\% out of the entire European Union network), however most are located close to urban centers. The additional daily observations taken from the schools can be an important addition to the overall reporting network. This is particularly true if the schools contribute from regions where monitors are not located or from locations downwind of industrial or urban locations and are able to capture potential pollution transport events. Another attribute of the student data is that they can be transmitted in near real-time. This feature is important when attempting to use the data for providing insight into potentially unusual sporadic events such as transport from nearby large wildfires. 


\section{THE CHALLENGES IN DEVELOPING AN ENVIRONMENTAL EDUCATION PROGRAM}

\section{A National Commitment in the Czech Republic}

In fulfillment of its mission, the GLOBE program set out to enhance environmental awareness of individuals throughout the world, contribute to scientific understanding of the Earth, and support improved student achievement in science and mathematics. The data and analysis described in this study have succeeded in achieving these goals because the Ministry of Education at the national level has supported environmental education by integrating it throughout all subject curricula in all grades. One noteworthy example of this integration occurs when elementary students are learning the English language: As part of the curriculum, environmental issues, such as the greenhouse effect and the ozone layer, are discussed in English to help learn the language.

At the student level, a sense of ownership and an understanding of the value of their data are instilled at a relatively young age. Making the connection between the data measured and the analysis and utility of the data is vital from an educational perspective and it all starts with fostering student inquiry. Educators want the students to feel a part of the scientific process and to be able to see how their data collection and analyses fit into the larger picture. In the case of the study described above, the S.M.O.G. team put together a poster detailing this important scientific finding and emphasizing the importance of the long-term surface ozone records compiled at several of these Czech schools. This poster (Henderson et al., 2005) was then presented at the 2005 Annual GLOBE Conference, 
coincidently held in Prague. Thus, many of the students and teachers in the Czech Republic who had been involved in the data collection were able to see their measurements formally presented and displayed at a large international conference.

\section{The S.M.O.G. Program in the U.S.}

In the United States, more than 7500 surface ozone measurements have been taken by 87 schools, second only to the Czech Republic in terms of number of measurements. Currently though, only a small number of elementary and secondary schools are actively participating in the Surface Ozone Protocol. The involvement is usually for a finite period of time and the level of participation appears to be driven by what is required, such as state and national education standards. And unlike the Czech measurements, the schools that do participate do not have consistent enough records for use in scientific analyses and most do not take readings during the important summer ozone season. One noteworthy U.S. school, The Most Pure Heart of Mary in Mobile AL, has been taking measurements since 2000. Fig. 9 shows the May 2005 relationship between the school measurements and the nearest EPA monitor measurements, also located in Mobile. As also seen with the Czech measurements (Fig. 8), good agreement between the two is evident, providing additional support for the quality of student measurements. Scientists from the S.M.O.G. team working with this school also analyzed another set of special observations taken hourly over a 2-day period that illustrated the capability of GLOBE data to capture the large diurnal variability often found for ozone (http://www.globe.gov/tctg/ozone.pdf?sectionId=15\&rg=n\&lang=en). 


\section{Lessons Learned}

Based on our experiences with the Surface Ozone Protocol, several important themes should be emphasized when starting up a GLOBE program.

1. Teacher Training: Both educators responsible for curriculum development and teachers who will actively use the S.M.O.G. protocol should attend the special train-the-trainer workshops. Particular emphasis should be placed on teacher exposure to exemplary curricula, including examples of hands-on, inquiry-based investigations. Professional development on curriculum integration, finding and using ancillary data (e.g., National Weather Service data, EPA Air Monitoring Station data), and "how to" lessons on using technology tools and software should also be included.

2. Mentoring: Interaction and communication with the protocol science teams are important for clarification, especially early in the training process so that erroneous procedures that compromise the quality of the information are not proliferated.

3. Scheduling: Teachers need to be afforded the appropriate time to integrate researchbased experiences for students into their classrooms.

Teachers, at gatherings such as the MY NASA DATA Workshop (http://mynasadata.larc.nasa.gov/) held each summer at NASA Langley Research Center, have expressed a strong interest in integrating GLOBE protocols into their curriculum. In schools that are having difficulty getting started, the Surface Ozone Protocol team has performed educational outreach and provides the following lessons learned: 
1. Organize area teams for data gathering, clusters of schools with teams composed of 2-3 teachers and 2-3 community members from each school.

2. Develop and implement surface ozone programs in both educational and noneducational settings. Some successful examples include the Smithsonian Museum of Natural History in Washington DC, the Christa McAuliffe Planetarium in Concord NH, and the Virginia Air and Space Center in Hampton, VA.

3. Train teachers, students, and community members to facilitate year-round data gathering, keeping in mind that summer data tend to be the most interesting.

\section{Conclusion}

Stories such as the Czech students' surface ozone measurements using the Surface Ozone Protocol or the validation of MODIS data with student aerosol observations from the Netherlands using the Aerosol Protocol are only two of the many successful uses of GLOBE data in scientific analyses. Continued support for these and similar efforts is important for both the educational and scientific communities.

In summary, the data presented in this study show that student observations can be used for a meaningful scientific study that provides the students with unique environmental insight that could not have been achieved from traditional teaching methods. However, the exciting findings described in the analysis of these data could not have been realized without support from all levels of the Czech educational system, starting with a national commitment to environmental education. In order to attain the kind of success achieved 
by the Czech schools, a commitment at the state and national level would seem to be a logical first step.

\section{ACKNOWLEDGEMENTS}

The authors would like to thank the teachers Sister Shirley Ann Boucher of the Most Pure Heart of Mary School and Pavla Černochová, Hana Kožišková, František Kynčl, Roman Rydval, Lucie Starčevská, and Marie Stratilová of the Czech schools and their students for their continued dedication to the GLOBE program and the Surface Ozone Protocol. We would like to thank Xiaojing Xu (SSAI) and Denise Stefula (SSAI) for their help in getting the figures and manuscript in final form. Funding for GLOBE was provided by the National Science Foundation. This work was also supported through the NASA Langley Research Summer Scholars (LARSS) Program and NASA's Atmospheric Chemistry, Modeling, and Analysis Program. 


\section{REFERENCES}

Ault, T. W., K. P. Czajkowski, T. Benko, J. Coss, J. Struble, A. Spongberg, M. Templin, and C. Gross, 2006: Validation of the MODIS snow product and cloud mask using student and NWS cooperative station observations in the Lower Great lakes Region. Remote Sens. Environ., 105, 341-353.

Bell, M. L., A. McDermott, S. L. Zeger, J. M. Samet, and F. Dominici, 2004: Ozone and short-term mortality in 95 U.S. urban communities. J. Amer. Med. Assoc., 292, 23722378.

Boersma, K.F., and J.P de Vroom, 2006: Validation of MODIS aerosol observations over the Netherlands with GLOBE student measurements. J. Geophys. Res., 111, D20311, doi:10.1029/2006JD007172.

Chambers, L.H., and D.P. Duda, 2005: Count-a-thon of airplane contrails. Eos Trans. $A G U, \mathbf{8 6}(41), 382$.

EEA, 2003: Air pollution by ozone in Europe in summer 2003. EEA Topic report, 3/2003. 
EEA, 2006: Air pollution by ozone in Europe in summer 2005. EEA Technical report, $3 / 2006$.

Fishman, J., 1991: The global consequences of increasing tropospheric ozone concentrations. Chemosphere, 22, No. 7, 685-695.

Heck, W.H., R.M. Adams, W.W. Cure, A.S. Hoagle, H.E. Heggestad, R. Kohut, L.W. Kress, J.O. Rawlings, and O.C. Taylor, 1983: A reassessment of crop loss from ozone. Environ. Sci. Tech., 12, 17:573A-581A.

Henderson, B., M. Pippin, J. Fishman, and J. Creilson, 2005: TEREZA Association for Environmental Education, and Students and Teachers of the Czech Republic, 2005:

Trends and Distributions of Surface Ozone Measured at Czech GLOBE Schools. 2005 Annual GLOBE Conference, Prague, Czech Republic.

IPCC (Intergovernmental Panel on Climate Change), 1996: Climate Change 1995: The Science of Climate Change. Cambridge University Press, Cambridge, UK.

Kalnay, E., and Coauthors, 1996: The NCEP/NCAR 40-year reanalysis project. Bull. Amer. Meteor. Soc., 77, 437-471.

Koren, H. S., and Coauthors, 1989: Ozone-induced inflammation in the lower airways of human subjects. Amer. Rev. Respir. Dis., 139, 407-415. 
Luterbacher, J., D. Dietrich, E. Xoplaki, M. Grosjean, and H. Wanner, 2004: European seasonal and annual temperature variability, trends, and extremes since 1500. Science, 303, 1499-1503.

Mauzerall, D. L., and X. Wang, 2001: Protecting agricultural crops from the effects of tropospheric ozone exposure: Reconciling science and standard setting in the United States, Europe, and Asia. Annu. Rev. Energy Environ., 26, 237-268.

Mims, F. M., III, 1999: An international haze-monitoring network for students. Bull. Amer. Meteor. Soc., 80, 1421-1431.

Spektor D.M., M. Lippmann, P.J. Lioy, G.D. Thruston, K. Citak, D.J. James, N. Bock, F.E. Speizer, and C. Hayes, 1988: Effects of ambient ozone on respiratory function in active, normal children. Amer. Rev. Respir. Dis., 137, 313-320.

Turco, R. P., 1997: Earth Under Siege From Air Pollution to Global Change. Oxford University Press, $527 \mathrm{pp}$. 


\section{FIGURE CAPTIONS}

1. Fig. 1. Number of monthly measurements submitted to the GLOBE Web site is shown from 2001 through 2005. Most of the measurements are from the Czech Republic (in red) and the United States (in blue); "Other Countries" includes data submitted by students from the following countries in order of number of measurements made: Spain, Croatia, Ghana, Dominican Republic, Lebanon, Panama, Canada, Chile, Sweden, Cameroon, and Cyprus. This figure illustrates the consistency of the Czech Republic student measurements, especially during the summer season.

2. Fig. 2. Irene Ladd, a member of the S.M.O.G. team, provides hands-on instruction in the use of the hand-held ozone measuring device to students from the Czech Republic.

3. Fig. 3. Students at the instrument shelter at the Kadan̆ School in the Czech Republic.

4. Fig. 4. Map depicting the location of the six schools that were recognized for their ozone records. The TEREZA Association is located in Prague. (Map courtesy of Www.graphicmaps.com).

5. Fig. 5. Time series of the two schools, Jičín (top panel) and Vítkov (bottom panel), with the longest and most complete ozone records.

6. Fig. 6. Average number of exceedances per station for European region stations which reported at least one exceedance. European region consists of three groups of countries: 
Northwestern (UK, Ireland, Netherlands, Belgium, Luxembourg, and France north of $45^{\circ}$ latitude), Central/Eastern (Germany, Poland, Czech Republic, Slovakia, Hungary, Austria, and Switzerland), and Southern (France south of $45^{\circ}$ latitude, Portugal, Spain, Italy, Slovenia, Greece, Cyprus, and Malta). * No station in the southern Europe group reported ozone data in 1996. (EEA, 2006).

7. Fig. 7. Average summer surface ozone and surface temperature measurements made by students at Czech Republic schools located in Jičín (blue) and Vítkov (red) from 2001 to 2005. Ozone anomalies for Jičín and Vítkov for the summer of 2003 were 57 ppbv and $10 \mathrm{ppbv}$, respectively; while temperature anomalies for the same time period were $1.7^{\circ} \mathrm{C}$ for Jičín and $1.8^{\circ} \mathrm{C}$ for Vítkov.

8. Fig 8. Hourly surface ozone measurements from a nearby CHMI reporting station in Hradec-Kralove (35 km from Jičín) during May 2004 (black time series); May 2004 daily student measurements from the Czech school at Jičín (red triangle); and the May 2004 daily CHMI station measurement made at the same time as the student measurement (blue diamond). CHMI data can be found at http://www.chmi.cz/indexe.html.

9. Fig. 9. Hourly surface ozone measurements from an EPA reporting station located in Mobile, Alabama during May 2005 (black time series); May 2005 daily student measurements from The Most Pure Heart of Mary School also located in Mobile, Alabama (red triangle); and the May 2005 daily EPA station measurement made at the 
same time as the student measurement (blue diamond). EPA data can be found at http://www.epa.gov/ttn/airs/airsaqs/detaildata/requestingaqsdata.htm. 


\section{Number of Measurements}

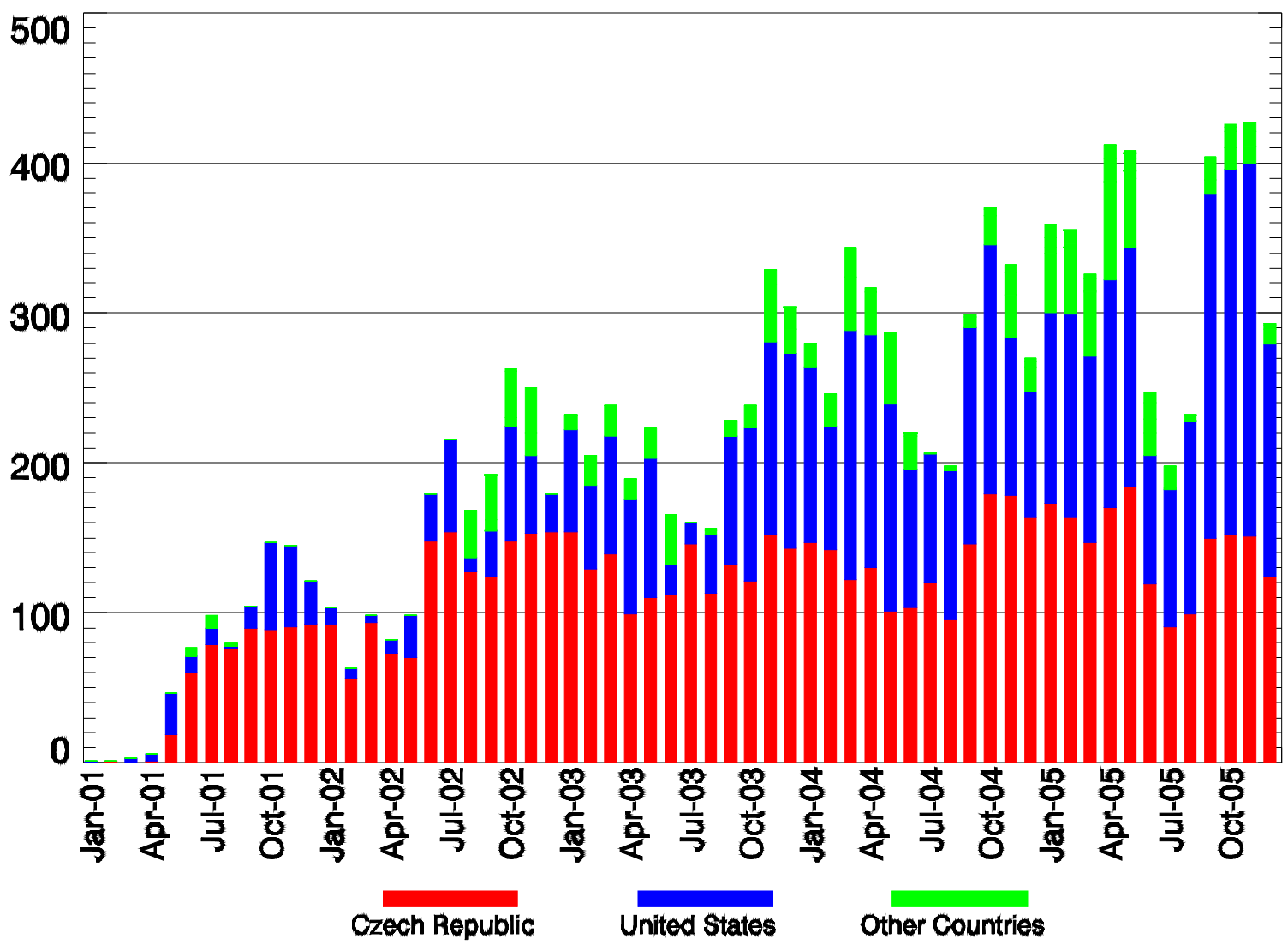

Fig. 1 Number of monthly measurements submitted to the GLOBE Web site is shown from 2001 through 2005. Most of the measurements are from the Czech Republic (in red) and the United States (in blue); "Other Countries" includes data submitted by students from the following countries in order of number of measurements made: Spain, Croatia, Ghana, Dominican Republic, Lebanon, Panama, Canada, Chile, Sweden, Cameroon, and Cyprus. This figure illustrates the consistency of the Czech Republic student measurements, especially during the summer season. 


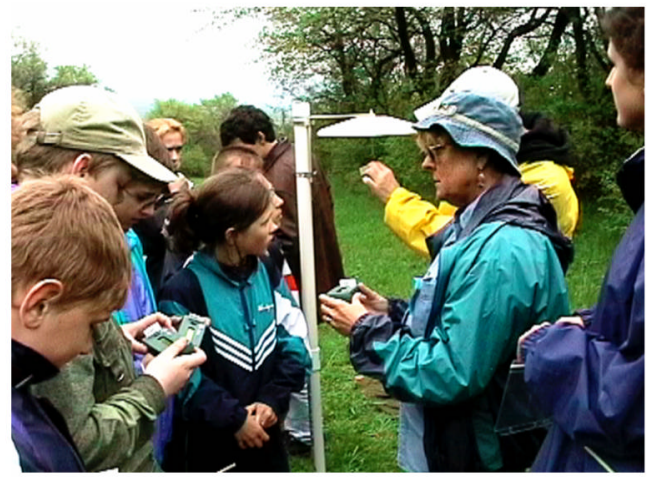

Fig. 2. Irene Ladd, a member of the S.M.O.G. team, provides hands-on instruction in the use of the hand-held ozone measuring device to students from the Czech Republic. 


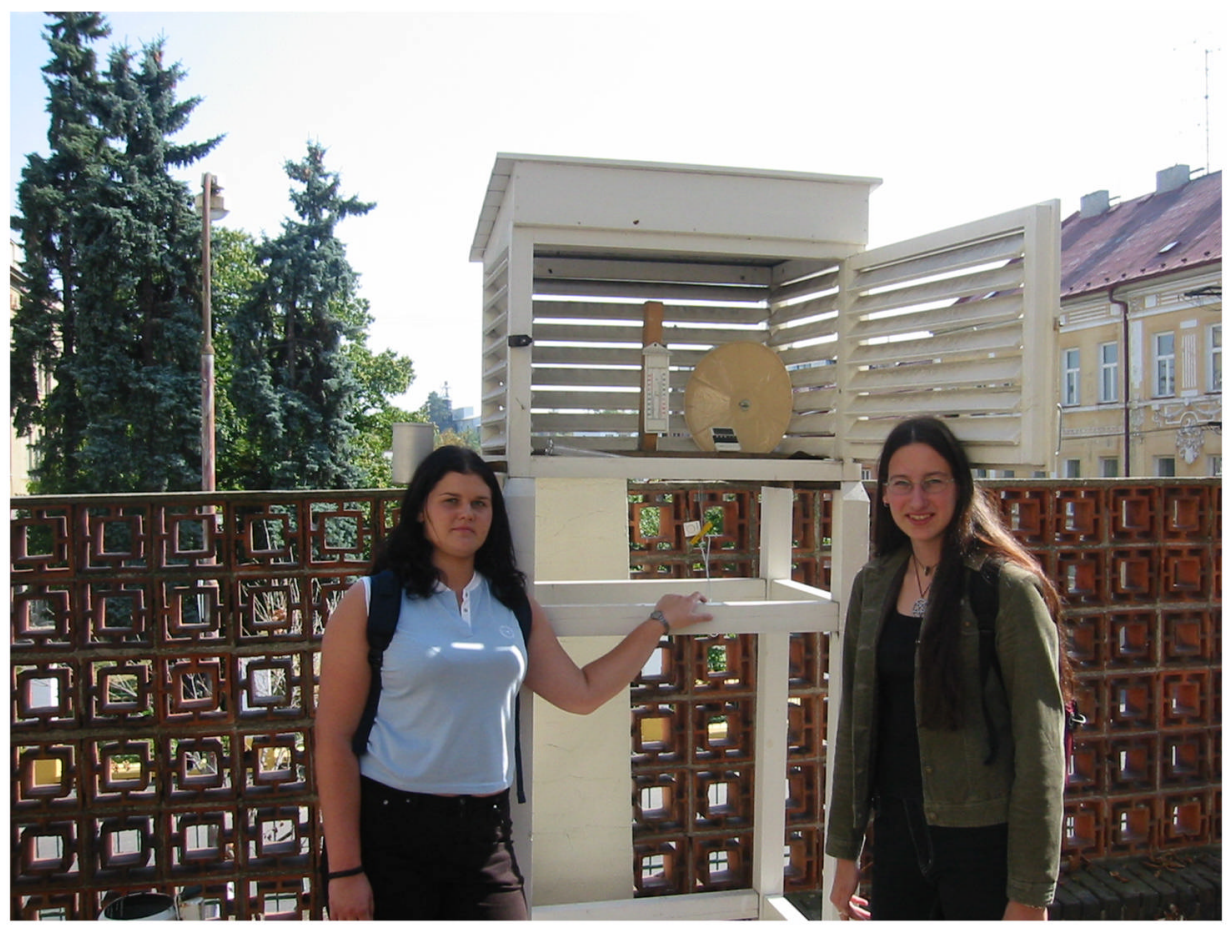

Fig. 3. Students at the instrument shelter at the Kadaň School in the Czech Republic. 


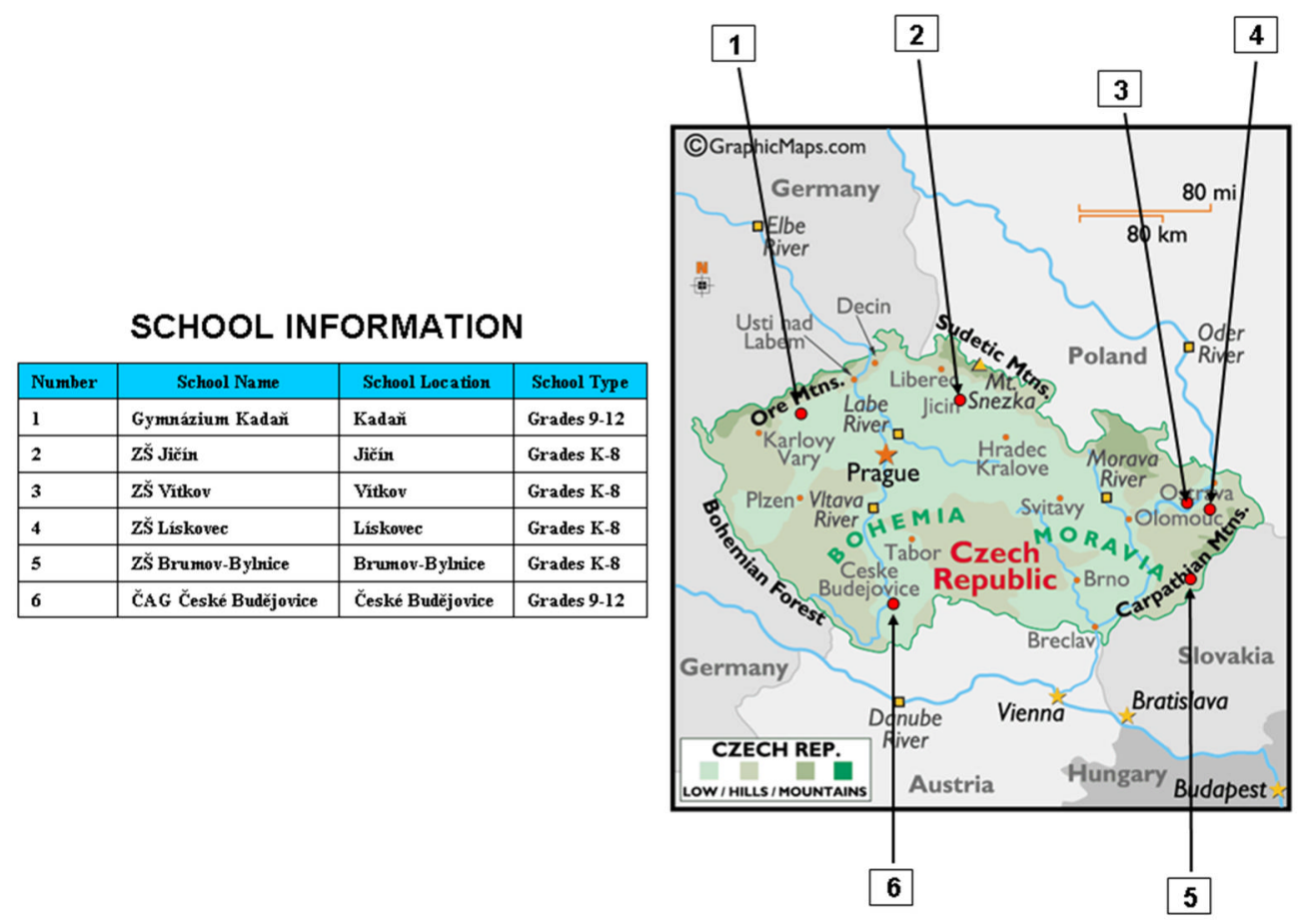

Fig. 4. Map depicting the location of the six schools that were recognized for their ozone records. The TEREZA Association is located in Prague. (Map courtesy of www.graphicmaps.com). 

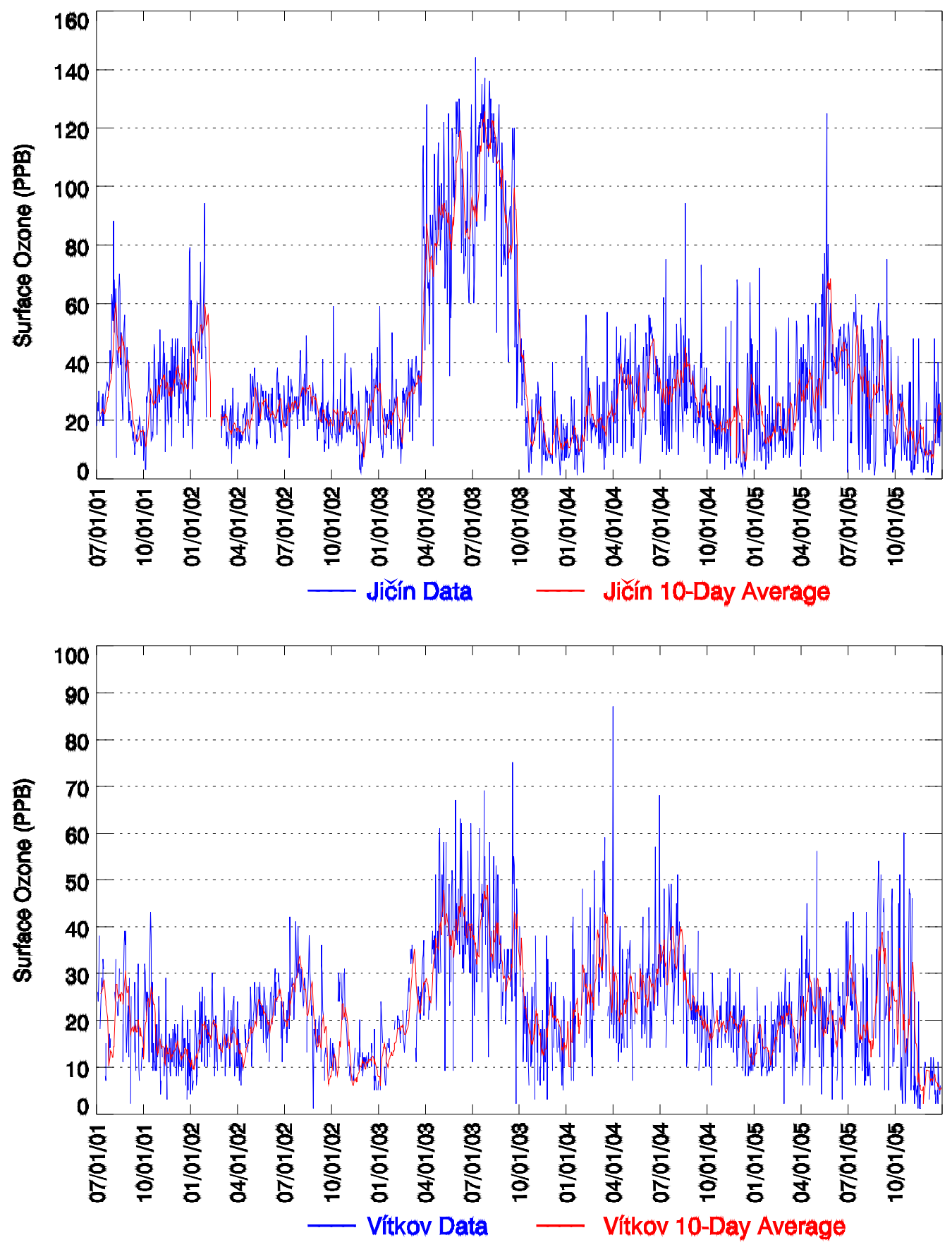

Fig. 5. Time series of the two schools, Jičín (top panel) and Vítkov (bottom panel), with the longest and most complete ozone records. 


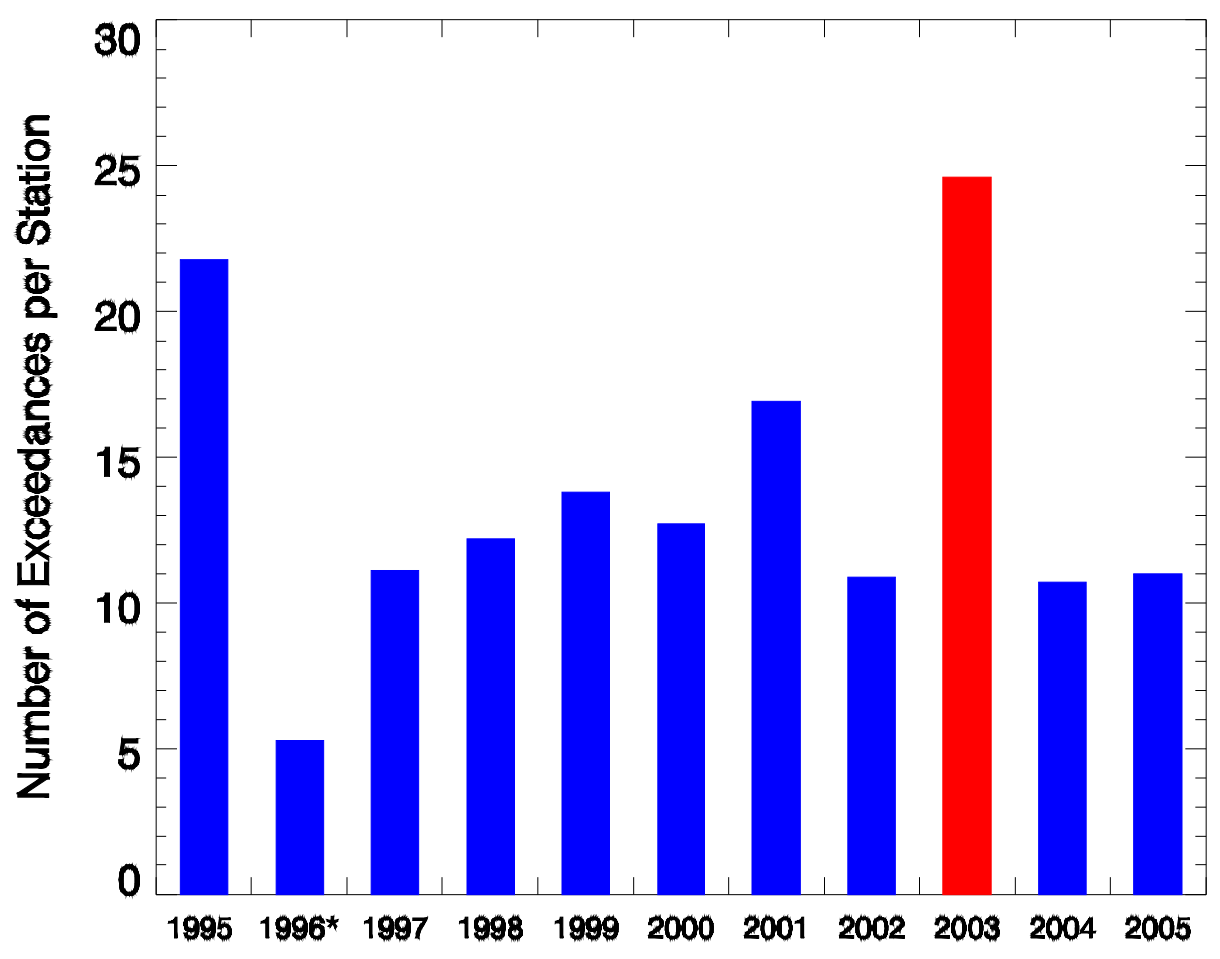

Fig. 6. Average number of exceedances per station for European region stations which reported at least one exceedance. European region consists of three groups of countries: Northwestern (UK, Ireland, Netherlands, Belgium, Luxembourg, and France north of $45^{\circ}$ latitude), Central/Eastern (Germany, Poland, Czech Republic, Slovakia, Hungary, Austria, and Switzerland), and Southern (France south of $45^{\circ}$ latitude, Portugal, Spain, Italy, Slovenia, Greece, Cyprus, and Malta). * No station in the southern Europe group reported ozone data in 1996. (EEA, 2006). 


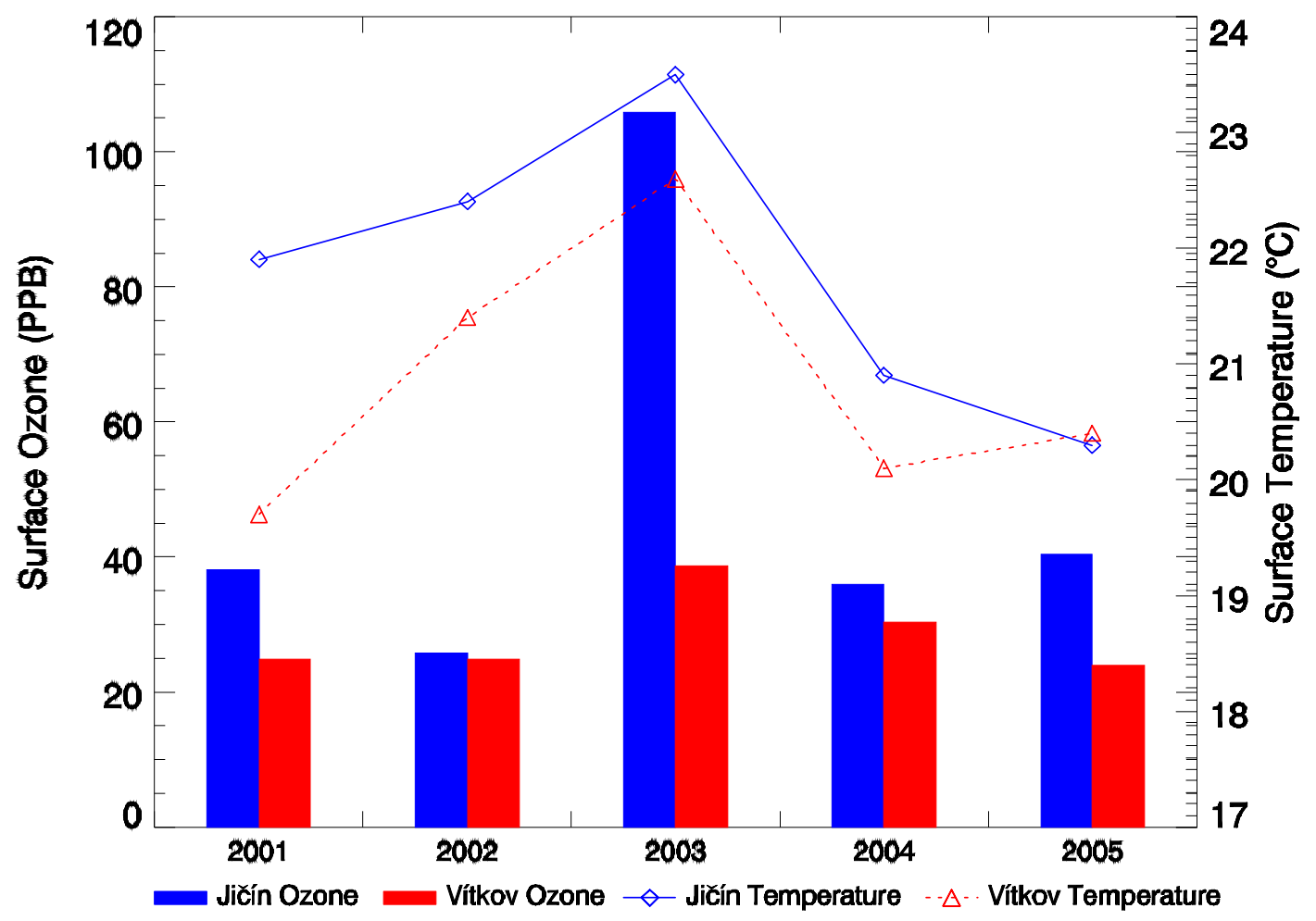

Fig. 7. Average summer surface ozone and surface temperature measurements made by students at Czech Republic schools located in Jičín (in blue) and Vítkov (in red) from 2001 to 2005. Ozone anomalies for Jičín and Vítkov for the summer of 2003 were 57 ppbv and 10 ppbv, respectively; while temperature anomalies for the same time period were $1.7^{\circ} \mathrm{C}$ for Jičín and $1.8^{\circ} \mathrm{C}$ for Vítkov. 


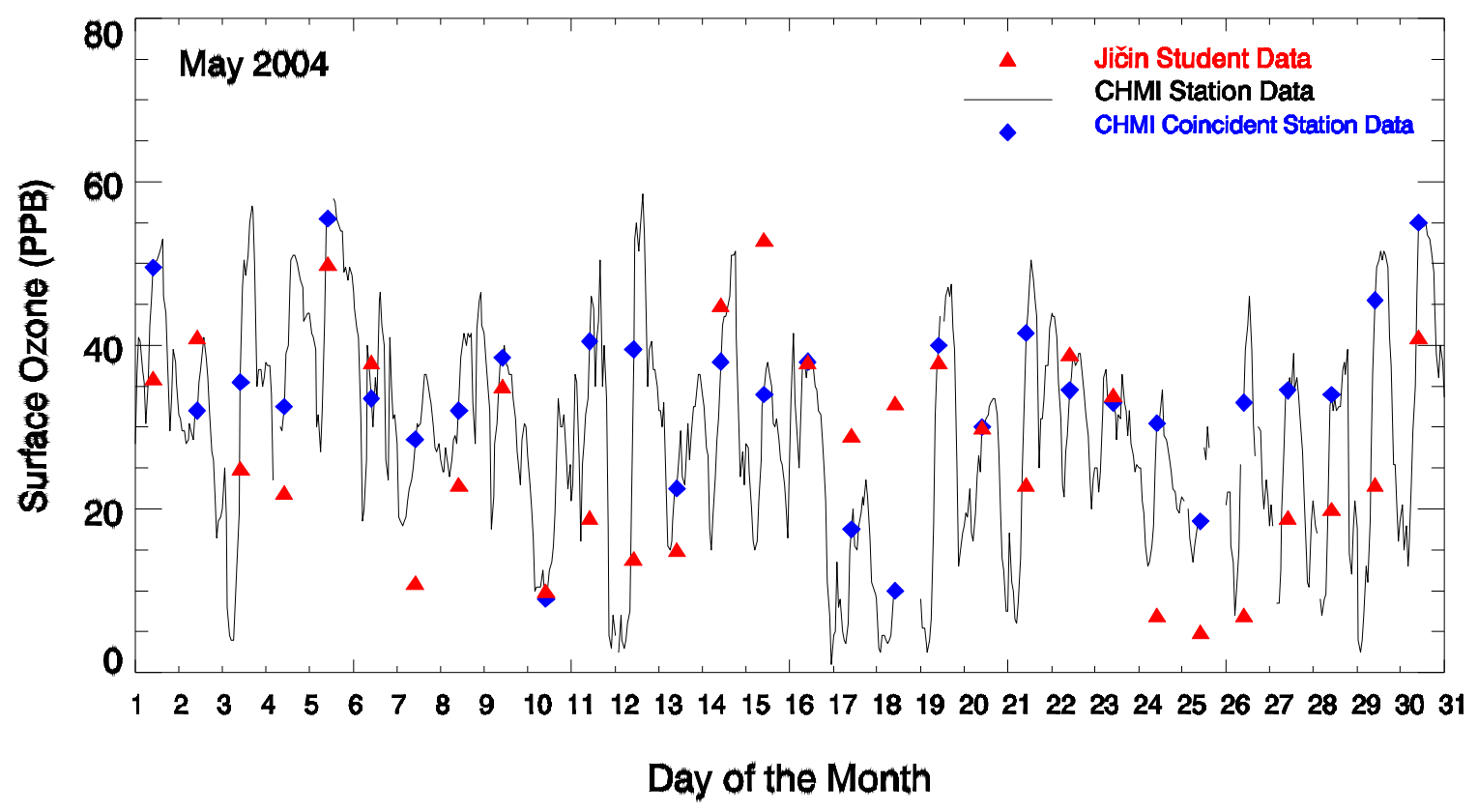

Fig 8. Hourly surface ozone measurements from a nearby CHMI reporting station in Hradec-Králové (35 km from Jičín) during May 2004 (black time series); May 2004 daily student measurements from the Czech school at Jičín (red triangle); and the May 2004 daily CHMI station measurement made at the same time as the student measurement (blue diamond). CHMI data can be found at http://www.chmi.cz/indexe.html. 


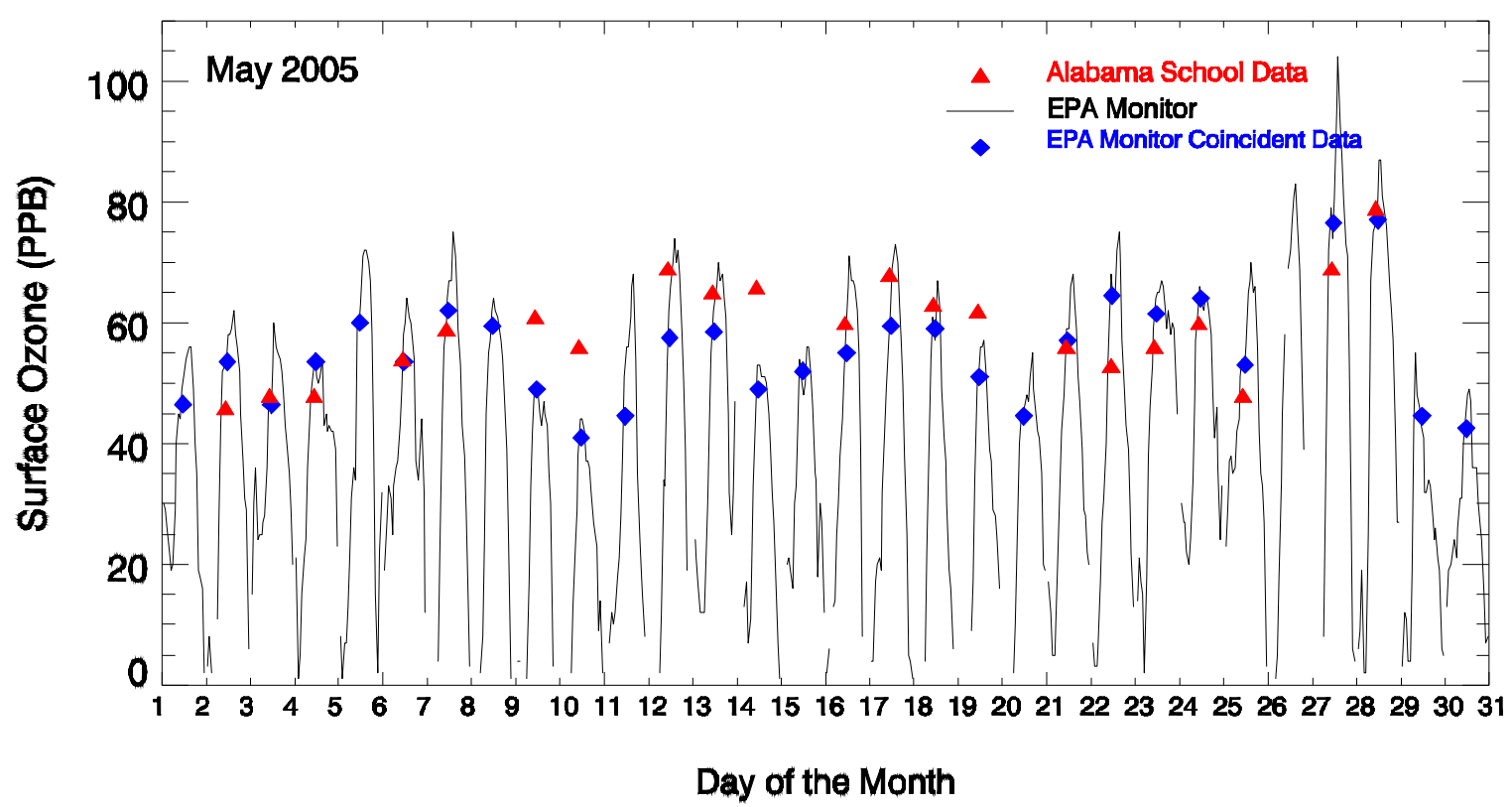

Fig. 9. Hourly surface ozone measurements from an EPA reporting station located in Mobile, Alabama during May 2005 (black time series); May 2005 daily student measurements from The Most Pure Heart of Mary School also located in Mobile, Alabama (red triangle); and the May 2005 daily EPA station measurement made at the same time as the student measurement (blue diamond). EPA data can be found at http://www.epa.gov/ttn/airs/airsaqs/detaildata/requestingaqsdata.htm. 